\title{
BMJ Open The Veterans Metrics Initiative study of US veterans' experiences during their transition from military service
}

To cite: Vogt D, Perkins DF, Copeland LA, et al. The Veterans Metrics Initiative study of US veterans' experiences during their transition from military service. BMJ Open 2018:8:e020734. doi:10.1136/ bmjopen-2017-020734

- Prepublication history for this paper is available online. To view these files, please visit the journal online (http://dx.doi org/10.1136/bmjopen-2017020734).

Received 21 November 2017 Revised 11 April 2018 Accepted 16 April 2018
Check for updates

For numbered affiliations see end of article.

Correspondence to

Dr Dawne Vogt:

dawne.vogt@va.gov

\section{ABSTRACT}

Purpose Efforts to promote the health and well-being of military veterans have been criticised for being inadequately informed of veterans' most pressing needs as they separate from military service, as well as the programmes that are most likely to meet these needs. The current article summarises limitations of the current literature and introduces The Veterans Metrics Initiative (TVMI) study, a longitudinal assessment of US veterans well-being and programme use in the first three years after they separate from military service. Veterans were assessed within 3 months of military separation and will complete five additional assessments at 6-month intervals during the subsequent period.

Participants The TVMI study cohort consists of a national sample of 9566 newly separated US veterans that were recruited in the fall of 2016.

Findings to date The TVMI sample includes representation from all branches of service, men and women, and officers and enlisted personnel. Although representative of the larger population on many characteristics, differential response rates were observed for some subgroups, necessitating the development of non-response bias weights. Comparisons between unweighed and weighted results suggest that the weighting procedure adequately adjusts for observed differences.

Future plans Analyses are under way to examine veterans' well-being and programme use in the period following separation after military service, as well as factors associated with poor outcomes. We have also begun to decompose programmes into their core components to facilitate examination of how these components relate to well-being. Once our third data collection is complete, we will examine factors related to different patterns of readjustment over time.

\section{INTRODUCTION}

Between 2014 and 2020, >1 million service members are expected to join the 2.3 million veterans who have already separated from the US military since the terrorist attacks of 11 September 2001. ' Although many individuals navigate the military-to-civilian transition successfully, some military veterans may

\section{Strengths and limitations of this study}

To our knowledge, this is the first longitudinal inves tigation of the military-to-civilian transition process within a national sample of post-9/11 US veterans.

- Another unique aspect of the study is the identification of components that are common to vocational financial, social and health programmes that are helpful to veterans.

- The involvement of federal and non-federal funders inclusion of study team members from multiple research settings and application of a multi-organisational data collection strategy allowed for a more comprehensive approach to the study than has been typical in prior research.

- As currently conceptualised, the study is limited to the first three years after separation from military service.

- Despite the application of non-response bias weights, there may still be some bias related to non-response and social desirability concerns.

find it difficult to transition from the highly structured military environment to an environment in which they must independently manage the challenges of securing civilian employment, managing finances, maintaining wellness and finding their place in the larger community. ${ }^{2-5}$ Transitioning to civilian role functions can be particularly complex for veterans with mental and physical health problems, which often impose additional burdens on coping skills and functioning. ${ }^{6-8}$

Along with the U.S. Department of Veterans Affairs (VA), >40000 organisations provide services intended to promote the readjustment of US veterans. ${ }^{6910}$ Although this represents an impressive commitment to supporting the veteran community, these efforts have been criticised for being inadequately informed of veterans' most pressing concerns after they separate from service, as well as the types of programmes that best meet their needs. ${ }^{2}{ }^{611-13}$ According to an 
Institute of Medicine report, ${ }^{6}$ the programmes that are available to veterans do not match the magnitude of the challenges they face, and many of veterans' needs are unmet or unknown.

Research conducted to date has been limited by narrowly defined research aims and a variety of methodological shortcomings. Below we briefly summarise these limitations, describe the role that the siloed nature of much of this research may play in explaining these limitations and introduce The Veterans Metrics Initiative (TVMI) study, a public-private partnership that was implemented to enhance knowledge about the military-to-civilian transition experience and inform efforts to better support transitioning veterans.

\section{Conceptual and methodological limitations of the veteran literature}

A recent review of studies on the readjustment of post9/11 veterans identified the lack of research on veterans' transition experiences as a key gap in the literature. ${ }^{14}$ Much of the research on veterans' postmilitary well-being is fielded many years after veterans separate from service or includes veterans with widely varying separation dates. As a consequence, this research is limited in its ability to address the concerns that are most relevant to veterans at the time of military separation. Many studies also rely on cross-sectional study designs, and thus, cannot speak to how veterans' needs change over time. ${ }^{14}$ Although a number of large-scale longitudinal studies have been implemented to provide insight into the effects of war-zone deployments on the health and health-related quality of life of US, UK and Canadian veterans (eg, $\left.\operatorname{refs}^{14-17}\right)$, to our knowledge, none of these studies has examined how veterans' needs change throughout the period immediately following their transition from service. For example, although the Millennium Cohort Study includes assessments from both the military and postmilitary time frame for some participants, that study was not designed to address the military-to-civilian transition experience and does not include closely spaced assessments initiated at the time of separation.

In addition, while the existing literature provides many valuable insights about veterans' health after they separate from service $\left(\mathrm{eg}, \mathrm{refs}^{18-20}\right)$, less is known about how veterans fare in terms of their employment, finances and social relationships. Although some studies have addressed these aspects of veterans' lives, the majority have focused on examining the impact of veterans' health on other aspects of life (ie, 'health-related quality of life') or have limited their samples to veterans with identified health concerns (eg, VA healthcare users), who are known to differ from the broader veteran population in numerous ways. ${ }^{814}$ Thus, a study that can provide a holistic assessment of veterans' well-being across multiple life domains is needed.

Knowledge regarding the programmes that veterans use as they transition from service, and those programmes that are most helpful to them, is also limited. Although
US veterans' engagement in VA programmes is welltracked, ${ }^{21}$ less is known about their use of programmes outside the VA. ${ }^{22}{ }^{23}$ In addition, high-quality information regarding the programmes that are most beneficial to veterans is largely unavailable, as rigorous evaluation and comparisons among programmes is rare in this literature. Likewise, comparisons with individuals who do not use programmes, the gold standard for clinical science, is rarely feasible in most programme evaluations. ${ }^{24-26}$

\section{Siloed nature of the veteran literature}

One factor that may account for some of these limitations is the siloed nature of much of the veteran research. ${ }^{12} 27$ With some exceptions, veteran studies are typically conducted by investigators from a single organisation (eg, VA) and focus on the concerns of a single funder. It is less common for researchers to come together from different research settings to address topics that are of interest to multiple stakeholders. Because of this, research findings on veterans' well-being are often not shared across settings, and lack of awareness of the research being conducted by others can lead to unnecessary duplication of efforts. Furthermore, projects that are limited to a single research setting or funding source tend to be more narrowly conceived, reducing their relevance for other contexts. Likewise, what can be accomplished in a study funded by a single source is more limited than what would feasible if multiple funders were to come together to pool their efforts. Finally, research that is perceived as 'owned' by any particular organisation may be vulnerable to concerns about the validity of study findings when veterans perceive (accurately or inaccurately) that their study participation has implications for access to desired benefits and services. Indeed, this narrow approach to study focus, investigator team and funding sources may explain, at least in part, why no longitudinal study has yet to provide a comprehensive examination of how veterans fare in multiple life domains as they transition from military service.

\section{TVMI study}

The TVMI study was designed to address these limitations by taking a partnered approach that included investigators from different organisational settings and disciplines, drew from multiple sources of public and private funding, and applied a multiorganisational data collection strategy that leveraged the unique strengths of both federal and private research settings. We describe this methodology below, after which we present information on the study sample and its representativeness, describe analyses that have been conducted to date and discuss future directions.

\section{Cohort description}

Origin of study concept

The TVMI study was initiated by the Henry M. Jackson Foundation for the Advancement of Military Medicine, Inc. (HJF), a private 501 (c) (3) not-for-profit organisation 
authorised by Congress to support research partnerships within the military medical community. In the absence of a government mandate to drive the work or legal authority over public-private research partnerships, HJF drew from the theory of 'Meta-Leadership' to guide the development of the TVMI study. ${ }^{28}$ Though born out of research on leadership in the face of natural and man-made threats, this model is broadly applicable to other efforts, including TVMI. Key dimensions of meta-leadership include understanding the needs, key stakeholders and critical options for action, communicating effectively to facilitate engagement and support, and creating 'community unity of purpose and effort.'

Recognising that diverse workgroups promote more creative problem solving, ${ }^{29}$ and increase productivity and scientific discovery, ${ }^{30}{ }^{31} \mathrm{HJF}$ worked with the TVMI study advisors to identify and recruit a multidisciplinary team of VA, Department of Defense (DoD) and civilian researchers willing to collaborate in this work. The research team that was selected includes six scientific Co-Principal Investigators, three from VA, one from the Clearinghouse for Military Family Readiness at the Pennsylvania State University, one from DoD and one from private industry (ICF). The group came together to develop the TVMI study protocol over a 3-year period, with input from a scientific advisory board, various stakeholders and a peer review.

\section{Formulation of study aims}

The study aims that were developed by the study team are to (1) document veteran well-being, as well as factors that predict changes in veteran well-being, throughout the transition and reintegration period; (2) identify programmes that veterans use as they reintegrate into civilian life and distil them into their common components; and (3) examine the link between common programme components and veteran well-being throughout the transition and reintegration process. Aim 1 fills an important gap by providing information on how veterans' needs change throughout transition and which veteran subgroups are most vulnerable to declines in well-being as they transition from service. Aims 2 and 3 move beyond the examination of whether particular programmes are associated with better outcomes to identify components that are common to programmes that are most effective in helping veterans. Study aim 1 is led by VA Co-PI Vogt, whereas study aims 2 and 3 are led by Penn State Co-PI Perkins, with support from the full research team. The study design that was developed is longitudinal, reflecting a 3-year prospective investigation that includes an initial assessment of well-being and programme use within approximately 3 months of separating from service followed by five additional assessments implemented at 6-month intervals thereafter. As of this writing, we have completed two of the six assessments and are currently fielding the third assessment.

\section{Identification of funders}

Consistent with the recognition that multiple funding sources provide a number of benefits, ${ }^{32} \mathrm{HJF}$ sought and secured funding for the TVMI study from a variety of public and private donors. Not only does the involvement of multiple funders allow investigators to extend research beyond the priorities of any individual funder, but it also reduces the likelihood that an individual funder will exert inappropriate control over the scientific process. ${ }^{33}$ Of course, the inclusion of multiple funders enhances the need for strong coordination and multiple reporting requirements. The TVMI study was designed with a strong administrative core to ensure adequate coordination among multiple public and private institutions and to facilitate effective management of multiple funding sources, tasks that can impede large collaborations. ${ }^{34}$

\section{Study population and public involvement}

Because a wide variety of stakeholders from veteran support organisations were and continue to be engaged in conversations with the study team about the relevance of TVMI data to the types of issues veterans face throughout the transition and reintegration process, the project is highly responsive to the priorities of those responsible for assisting veterans in their transition from military service. Prior to initiating the TVMI study, HJF hosted multiple stakeholder sessions to obtain input on the challenges faced by veterans and to garner support for the project within HJF, among federal and civilian researchers and leaders, and from both public and private funders. Stakeholder groups continue to have input on the focus of study analyses through their participation in regular meetings with study team members. The study has also benefited from the input of veterans themselves, as veterans are well-represented among the stakeholder groups that have been engaged in this research and members of the study population were consulted on the measurement of both well-being and programme use. In turn, results are shared with relevant stakeholders through the preparation of web-based informational materials, publication of study findings in academic journals and presentation of study findings in a variety of relevant venues, including regular in-person meetings with funders.

\section{Sample selection and data collection methodology}

Our goal in identifying the study sample was to select a sampling frame that was representative of the population of recently transitioned veterans. We identified the VA/DoD Identity Repository (VADIR), a VA-managed dataset that contains contact information for all separated service members, as a source that could meet this need. However, our ability to use this sampling frame was complicated by the fact that the veteran contact information contained within this dataset is considered personally identifying information (PII), and thus, may not be shared outside of VA. To meet the requirement to maintain veterans' PII within VA, while producing a dataset that would be accessible to all collaborators participating 
in this public-private partnership, we developed a unique data collection methodology that allowed us to disassociate veterans' PII from their survey data. This methodology involved splitting our outreach and data collection efforts. The outreach phase was implemented by our VA Boston collaborator, who identified potential participants through VADIR and sent them a letter that described the study and provided a link to the website of our private industry collaborator, ICF. Those who elected to participate in the study provided their contact information and completed the survey at this website using ICF's web-based data collection platform. This methodology allowed us to identify a nationally representative sampling frame of potential participants while maintaining VA PII within the VA setting. As such, we were able to generate a deidentified dataset that could be shared across research settings. This represents a significant achievement, given that regulatory requirements related to the protection of veteran data have traditionally made data-sharing difficult between VA and non-VA researchers. ${ }^{6}$

Our goal for the study sample was to include former service members from all branches/components (four Active Component service branches, plus activated National Guard/Reservists), men and women, and both former officers and enlisted personnel. We included activated National Guard/Reservists because they transition from more limited military service (typically one weekend a month and 2 weeks a year) to full-time military service in support of a deployment, and therefore, experience the same transition as members of the active component following an activation. We sought to recruit enough baseline sample members to ensure that we would be able to evaluate differences in estimates based on each of these groups at each wave of data collection. To generate estimates with an acceptable margin of error $( \pm 5 \%)$ and a confidence level of $95 \%$ (alpha $=0.05),{ }^{35}$ our aim was to retain at least 400 participants in each group by the end of wave 6 (eg, 400 Activated National Guard/Reservists). To accommodate expected attrition at subsequent assessments (estimated at 25\% for the second assessment and $10 \%$ for subsequent assessments), account for our smallest anticipated group (ie, women) and build in extra sample in case our response rate expectations were overly optimistic, we sought to enrol a nationally representative sample of 7500 veterans at the baseline assessment.

Because response rates tend to vary between $20 \%$ and $30 \%$ for surveys of US military personnel and veterans, ${ }^{36}{ }^{37}$ we conservatively estimated that we would obtain a response rate of $20 \%$ during the first survey administration. Based on this estimate, we planned to invite a minimum of 35500 randomly selected veterans from each of the three targeted groups to participate in the main baseline survey, in addition to 2000 randomly selected veterans included as an initial test of our survey methodology and instrument. We ultimately invited 48965 veterans to participate in the study when the opportunity arose to draw a sampling frame that included the entire universe of veterans who met our inclusion criteria at the time of our main data extraction (fall, 2016). The sampling frame was limited to veterans who had a mailing address within the continental USA and those who had separated from active duty service or from activated status with the Reserves within the last 90 days. Among National Guard/Reservists, only those who experienced an activation of at least 180 days were included and there was no restriction on whether they continued to serve in the Reserves following their deactivation from federal service.

The main data collection for the baseline survey used a modified Dillman mail survey procedure, ${ }^{38}$ which included mailing an initial postcard that introduced the study along with an opt-out postcard that veterans could return if they wished to stop receiving mailings. This was followed by a letter that provided information about how to participate, and finally, two reminder postcards (all sent 1 week apart). Given that the use of incentives to increase survey response rates is widely supported ${ }^{39}$ and prepaid survey incentives have been shown to be a particularly effective strategy, ${ }^{37} 40$ we included a pre-incentive of $\$ 5$ cash, coupled with a postsurvey $\$ 20$ electronic gift code. Five additional assessments are planned at 6-month intervals following the first wave of data collection. For each subsequent wave, the incentive will increase by $\$ 5$ (ie, $\$ 30$ for the second follow-up, $\$ 35$ for the third follow-up, etc). In addition, all participants are entered into random drawings for $\$ 100$ gift codes and small tokens of appreciation (eg, magnets) are provided at several points in the study.

The default mode for survey completion is via a web-based platform optimised for mobile devices. At baseline, a paper-and-pencil version of the survey was made available to participants on request; however, only 18 paper questionnaires were requested and only 11 participants completed surveys this way. The first survey, which took a median of $37 \mathrm{~min}$ to complete, addressed veterans' well-being and programme use, as well as other characteristics expected to impact veterans' experiences. Well-being was assessed with the Well-Being Inventory (WBI), a set of scales that was created to assess veteran well-being as part of a 4-year, multistudy psychometric development and validation procedure (Vogt et al, unpublished manuscript). This set of scales provides a comprehensive but efficient assessment of status, functioning and satisfaction across the four key life domains of vocational experiences, finances, mental and physical health, and social relationships. Unlike other measures that co-mingle different aspects of well-being, the WBI takes a multidimensional scoring approach that produces separate measures of the many different factors that serve as the 'building blocks' of well-being. Another key feature of the WBI is the inclusion of indicators of objective life circumstances. Whereas many measurement tools limit their focus to the assessment of functioning and/or satisfaction among those individuals who report participating in key life roles (eg, those who are employed or in intimate relationships), the inclusion of indicators of objective status in the WBI draws attention 
to the importance of considering engagement in key life roles as a core component of well-being.

Veterans were also asked a total of 37 questions about programmes they may have used since being discharged, in each of the four well-being domains described earlier. Twelve items were asked in the vocational domain (seven related to employment programmes and five focused on education); five questions were asked within the domain of legal, financial and housing; four questions in the health domain and five questions within the social/personal relationships domain. These programme questions were adapted from a list of veteran-serving organisations and programmes focused on positively influencing veteran functioning across well-being domains (eg, job identification and training, financial support for education, peer and community social support) that was developed by The Philanthropy Roundtable. ${ }^{41}$ Additional questions were created by the research team for the purpose of the study and the needs of the funding agencies.

Other factors that were assessed in the survey included military service experiences, exposure to stress and trauma over the life course, social support and resilience, all of which will be examined as potential predictors of well-being. In addition, the assessment of well-being was supplemented with measures of other related outcomes, including post-traumatic stress disorder, depression, anxiety, alcohol misuse, traumatic brain injury and reproductive health. The second survey, which was administered 6 months later, included the same core measures of well-being and programme use and also took a median of 37 min to complete. Measures of constructs that would be expected to change over time (eg, well-being, programme use, mental health, stress and trauma exposure) will be readministered in subsequent surveys, which had not yet been fielded at the time of this writing.

\section{FINDINGS TO DATE}

\section{Sample characteristics, representativeness and weighting}

A total of 9566 veterans completed the first assessment within the allotted time frame (6.5 weeks for pilot testing, 9.5 weeks for the main data collection, 16 weeks overall), and an additional 581 veterans submitted partial responses. This represents a $23 \%$ response rate, calculated after reducing the total number of those invited to participate (48 965) by the number of known undeliverable mailings (4682) and deceased individuals (2). A total of 7200 veterans completed the second assessment within the allotted time frame ( 8 weeks), and an additional 142 veterans submitted partial responses. This represents a $79 \%$ response rate, calculated after reducing the total number of those invited to participate (9566) by the number of known undeliverable mailings (274). The first column of table 1 includes demographic and military characteristics on the sample of veterans who enrolled in the TVMI study. As indicated there, the TVMI study sample includes representation from different branches and components of military service, and includes veterans across all paygrades as well as age groups. Although the majority of study participants are men, $24 \%$ are female veterans, and thus, subgroup analyses will be possible. Veterans who indicated having a minority racial or ethnic identity are also represented in the sample at a level that will support subgroup analyses.

The distribution of respondents in the TVMI study sample is similar to the original sampling frame on many key demographic and military categories, as indicated in the first two columns of table 1 . Several notable differences were observed however. Lower level enlisted service members were less likely to participate in the first wave of the study than officers, which likely also contributed to the finding that younger veterans were somewhat less likely to participate than older veterans (as officers tend to be older than enlisted personnel). In addition, previously activated National Guard/Reservist personnel were slightly less likely to participate than their active duty counterparts.

Because over-representation of some subgroups can threaten the generalisability of study findings, we computed non-response weights to adjust for differences observed on the three key military and demographic characteristics of gender, rank/paygrade and branch compared with the full population of 48965 veterans that met the criteria for eligibility. Cell weighting was computed by taking the total sample size of each group divided by the number of completed surveys within each cell. ${ }^{42}$ As indicated in the comparison of weighted and unweighed estimates in table 1 , this procedure adequately adjusted for observed differences based on the three weighting variables, as well as for differences observed in the likelihood of responding based on age.

Because differential drop-out over time may produce biased results, we also examined whether there were demographic or military subgroup differences in attrition between the first and second wave of the survey, which was administered 6 months later. Results suggested that differential attrition was not a substantial concern. Although comparisons based on age, race/ethnicity, branch of service and rank/paygrade were all statistically significant (the gender comparison was not), effect sizes corresponding to $\chi^{2}$ values (phis) were very small, ranging from 0.04 to 0.06 .

\section{Study analyses completed to date}

We have begun analyses to support aim 1's goal of examining veterans' well-being across key life domains and are in the process of preparing summaries of study findings based on the first and second wave of data collection for presentation and publication. Once we have three assessments completed, we will begin analyses focused on documenting differential trajectories of readjustment and predictors of these different patterns of readjustment. We have also made considerable progress with study aim 2 , which is focused on decomposing the programmes that veterans use as they reintegrate into civilian life into their common components, 
Table 1 Comparison of unweighed sample, sampling frame and weighted sample

\begin{tabular}{|c|c|c|c|}
\hline & $\begin{array}{l}\text { Unweighed sample } \\
(\mathrm{n}=9566), \%\end{array}$ & $\begin{array}{l}\text { Sampling frame } \\
(\mathrm{n}=48965), \%\end{array}$ & $\begin{array}{l}\text { Weighted } \\
\text { sample, \% }\end{array}$ \\
\hline \multicolumn{4}{|l|}{ Gender } \\
\hline Male & 81.8 & 84.1 & 84.1 \\
\hline Female & 18.2 & 15.9 & 15.9 \\
\hline \multicolumn{4}{|l|}{ Age (years) } \\
\hline $18-24$ & 19.4 & 28.6 & 26.6 \\
\hline $25-29$ & 22.3 & 25.2 & 25.4 \\
\hline 30-34 & 15.1 & 13.8 & 15.0 \\
\hline $35-39$ & 13.1 & 10.8 & 11.2 \\
\hline $40-44$ & 13.4 & 10.5 & 9.9 \\
\hline $45-49$ & 10.0 & 7.0 & 7.2 \\
\hline $50+$ & 6.8 & 4.2 & 4.9 \\
\hline \multicolumn{4}{|l|}{ Racial ethnic/minority status } \\
\hline Not minority race/ethnicity & 65.8 & 63.5 & 63.4 \\
\hline Minority race or ethnicity & 34.2 & 36.5 & 36.6 \\
\hline \multicolumn{4}{|l|}{ Service branch/component } \\
\hline Army & 33.3 & 32.1 & 32.1 \\
\hline Navy & 19.2 & 18.8 & 18.8 \\
\hline Air Force & 18.9 & 13.5 & 13.5 \\
\hline Marines & 15.9 & 17.2 & 17.2 \\
\hline National Guard/Reserves & 12.7 & 18.4 & 18.4 \\
\hline \multicolumn{4}{|l|}{ Paygrade } \\
\hline E1-E4 junior enlisted & 28.3 & 41.4 & 41.4 \\
\hline E5-E6 mid-grade enlisted & 30.0 & 29.5 & 29.5 \\
\hline E7-E9 senior enlisted & 17.2 & 13.4 & 13.4 \\
\hline W1-W5 warrant officers & 1.5 & 1.1 & 1.1 \\
\hline O1-O3 junior officers & 8.7 & 6.4 & 6.4 \\
\hline O4-O10 senior officer & 14.1 & 8.1 & 8.1 \\
\hline
\end{tabular}

Ns vary due to missing data.

which will allow us to identify components associated with improvements in veteran well-being (study aim $3)$. This systematic coding process draws on information available on programmes' website and/or annual reports to identify components of programmes identified by veterans. ${ }^{43}$ The common components include (1) content components, what is taught or provided by the programme (eg, skills taught, knowledge/information, problem-solving, coping skills); (2) process components-the delivery mode (eg, online, face-toface) and methods (eg, self-paced, direct instruction, modelling, role-playing, practice); (3) barrier reduction components (eg, providing monetary or other tangible support, providing transportation, reducing stigma to increase programme utilisation); and (4) sustainability components (eg, ongoing social support groups, community support, referrals).

In cases where no website is available $(8 \%$ of programmes identified during the first assessment), a semistructured interview with the programme developer/implementer is conducted. To ensure consistency in coding, codes based on information gleaned from programme websites are compared with codes based on interviews with programme developers/ implementers for a random subset of programmes $(10 \%)$. Once all coding is complete, the components will be attributed back to the veteran who named the programme through a data merge process. In this way, even quite small programmes can be distilled into their core components. This coding procedure, which is being completed for all programmes identified by a minimum of three respondents, has allowed us to capture information on components of programmes used by $90 \%$ of the respondents who named a specific programme within each well-being domain during the first assessment. Programmes nominated in the follow-up surveys will be similarly coded. 
Past Work

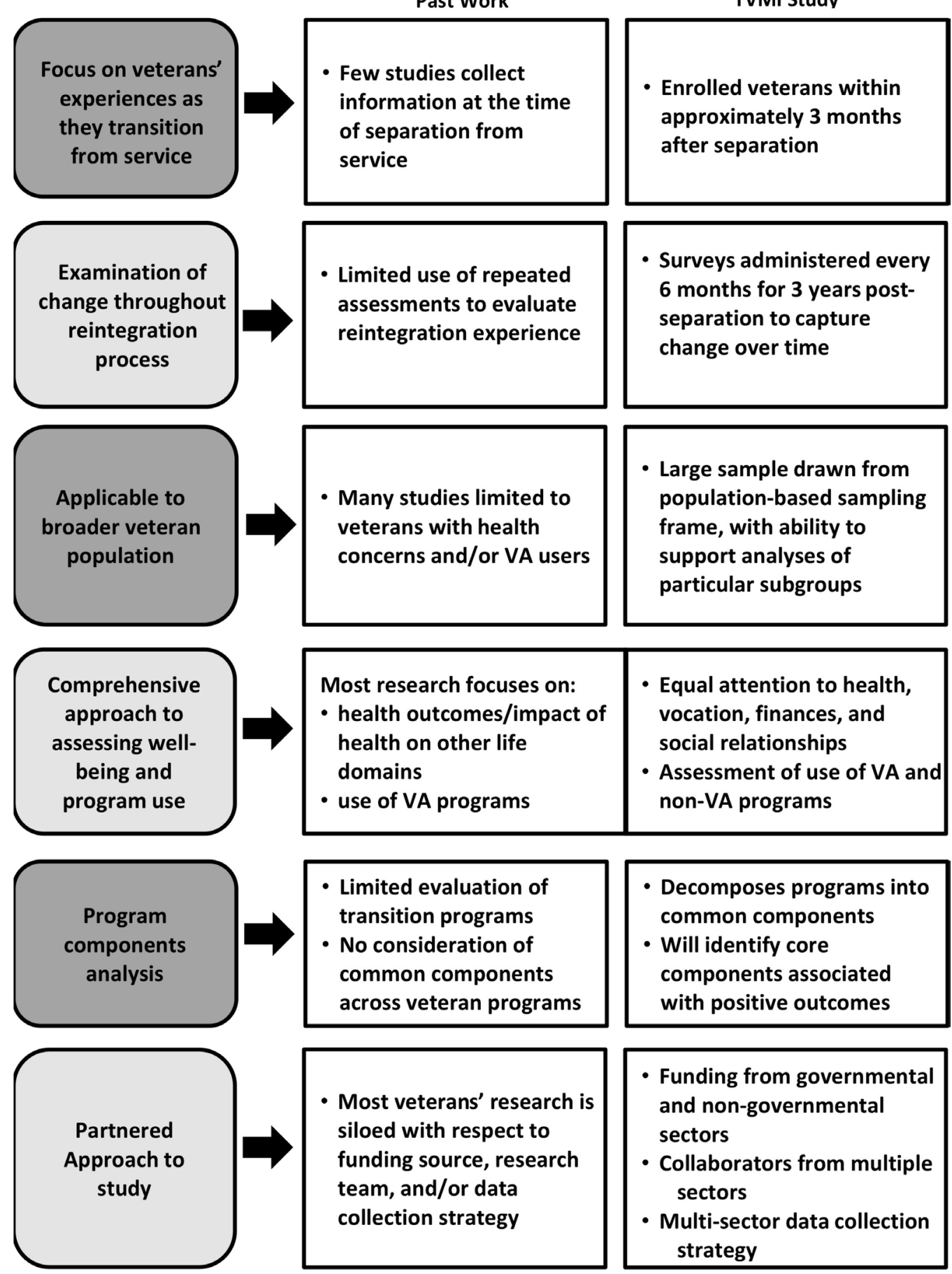

Figure 1 Key aspects of the The Veteran Metrics Initiative (TVMI) study. VA, U.S. Department of Veterans Affairs.

\section{Strengths and limitations}

The TVMI study was implemented to provide insight into veterans' most pressing needs as they separate from military service and to inform the efforts of veteran support organisations dedicated to meeting these needs. To our knowledge, this study represents the first large-scale investigation of how veterans' experiences unfold as they separate from military service, and thus, fills a critical gap in the literature. ${ }^{1424}$ As indicated in figure 1, the TVMI study builds on best practices and introduces a number of novel methodological approaches that will enhance knowledge of veterans' experiences after they separate from military service. These factors include its (1) focus on veterans' experiences as they transition from military service; (2) examination of how veterans' needs change through the reintegration process; (3) broad applicability to the veteran population; (4) comprehensive approach to assessing veterans' well-being and programme use; (5) identification of core components of programmes that are helpful to veterans' reintegration; and (6) application of a partnered approach to the identification of funding sources, study team members and data collection methodology. 


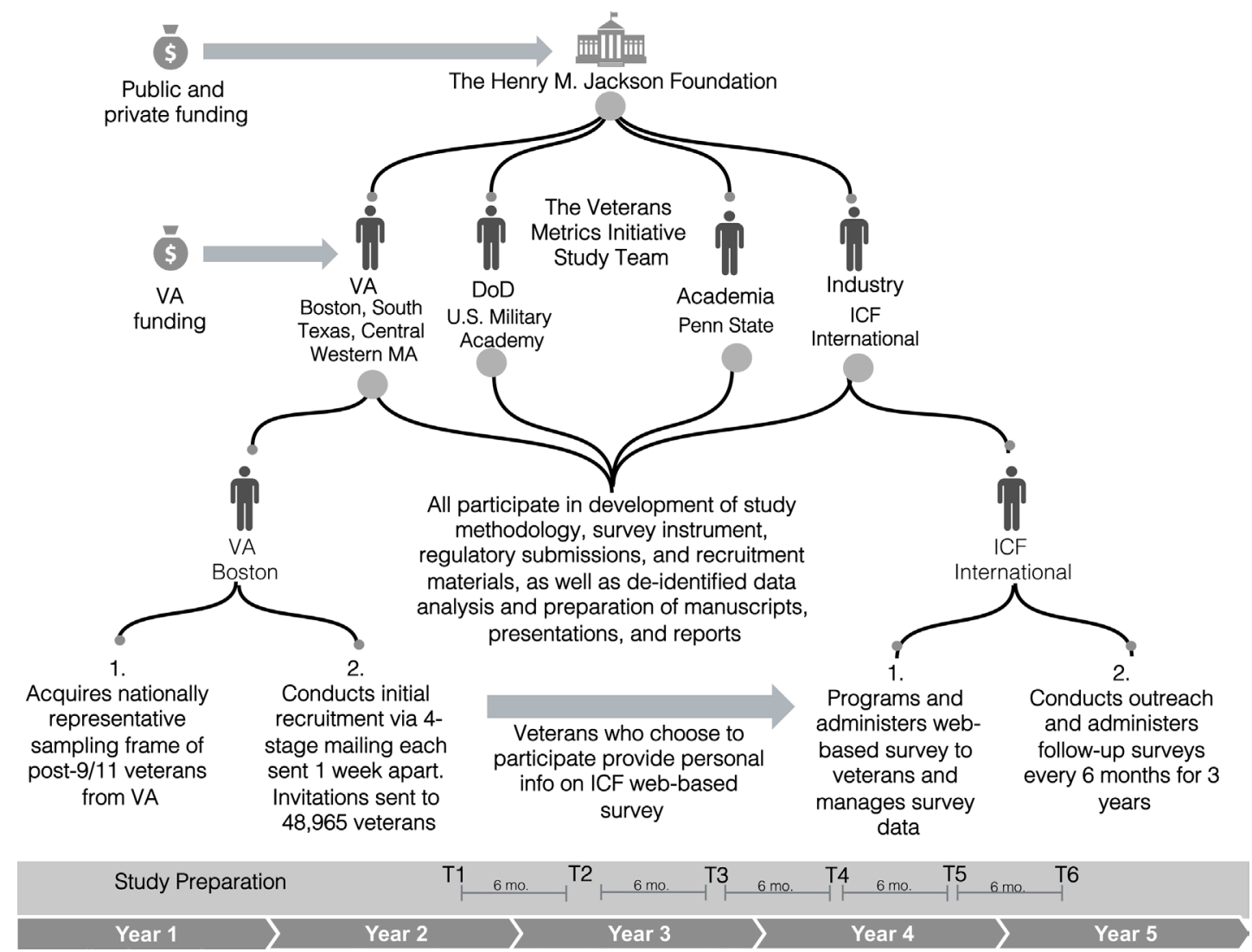

Figure 2 Nature of the The Veteran Metrics Initiative study public-private research partnership. DoD, Department of Defense; VA, U.S. Department of Veterans Affairs.

As depicted in figure 2, a unique aspect of the TVMI study is the implementation of a partnered approach that leverages the unique strengths of public and private collaborators. This approach has many benefits. For example, whereas much of the research conducted in the VA healthcare system understandably focuses on veterans' health, the inclusion of external funders allowed us to attend to other important aspects of veterans' lives independent of their health, including their vocational and financial wellbeing. Likewise, the inclusion of federal collaborators allowed us to access a sampling frame that would have been otherwise unavailable to non-governmental team members, who do not typically have access to population-based samples of veterans. ${ }^{6}$ Moreover, our partnered approach to data collection has made it possible to separate veterans' protected health information from their survey data, which will allow us to create a data repository that will be broadly available to researchers within and outside the VA setting. This is a substantial benefit as the challenges associated with accessing federal datasets are well-documented. ${ }^{6445}$

Despite these strengths, the TVMI study also has several limitations that must be acknowledged, including the relatively low response rate observed for the first assessment. Although low response rates increase the potential for non-response bias, it is important to note that this sample was fairly similar to the larger population on many characteristics and that we will apply weights to adjust for non-response bias based on demographic and military characteristics. Despite this, bias associated with unmeasured variables is always a possibility. Another aspect of the study that may be perceived as a weakness is the study's reliance on self-reports. Although many aspects of veterans' experiences addressed in this study are best addressed with self-reports, including subjective accounts of life satisfaction, ${ }^{46}{ }^{47}$ self-reports of some aspects of well-being, including functioning, may not be accurate in cases where individuals lack insight or intentionally misrepresent their experiences. We hope to supplement these self-report data with administrative data from federal sources, as well as assessments of family members, in the future. Finally, it is important to note that while all former National Guard/Reservists were activated for a deployment during their time of service, former Active Duty personnel may or may not have experienced a deployment during their military service. While the US military's increased reliance on the former group's military service in recent years underscores the importance of examining their transition experiences, comparisons between these groups should be made with caution.

\section{Future plans}

We have begun to examine veterans' well-being and programme use in the first year after military service, as well as factors that put veterans at risk for poor outcomes. The work of decomposing programmes into their 
core components is also under way. When this work is complete, we will examine how programme components relate to well-being and develop a menu of components that are common to programmes that predict improved well-being. A number of additional research questions will be addressed as future waves of data collection become available. For example, these data will support the examination of different patterns of readjustment over time, changes in programme use throughout the transition and reintegration process, and differences in women's and men's transition experiences. Should funding allow, we will continue to survey veterans beyond the 3-year time frame and explore opportunities to link these data with information derived from surveying family members and other relevant data sources (eg, DoD and VA administrative records).

\section{Author affiliations}

${ }^{1}$ Women's Health Sciences Division, National Center for PTSD (116B-3), VA Boston Healthcare System, Boston, Massachusetts, USA

${ }^{2}$ Department of Psychiatry, Boston University School of Medicine, Boston,

Massachusetts, USA

${ }^{3}$ Clearinghouse for Military Family Readiness, Pennsylvania State University (PSU),

State College, Pennsylvania, USA

${ }^{4}$ Department of Agricultural Economics, Sociology, and Education, Pennsylvania

State University, State College, Pennsylvania, USA

${ }^{5}$ Social Science Research Institute, Pennsylvania State University, State College,

Pennsylvania, USA

${ }^{6}$ VA Central Western Massachusetts Healthcare System, Leeds, Massachusetts, USA ${ }^{7}$ Center for Applied Health Research, Baylor Scott \& White Health, Temple, Texas, USA

${ }^{8}$ Department of Psychiatry, UT Health San Antonio, San Antonio, Texas, USA

${ }^{9}$ Veterans Evidence-based Research Dissemination and Implementation Center, South Texas Veterans Health Care System, San Antonio, Texas, USA

${ }^{10}$ Departments of Medicine and Psychiatry, UT Health San Antonio, San Antonio, Texas, USA

${ }^{11}$ The Henry M. Jackson Foundation for the Advancement of Military Medicine, Inc, Bethesda, Maryland, USA

${ }^{12}$ Westat Inc, Rockville, Maryland, USA

${ }^{13}$ ICF International Inc, Fairfax, Virginia, USA

Acknowledgements The authors thank Patricia Vanderwolf, John Boyle, Yael Nilni and Emily Taverna for their contributions to data collection. The authors would also like to thank Emily Bramande for assistance with the preparation of the manuscript.

Contributors DV, DFP, LAC, EPF, CSJ, BB, SL, and CLG all contributed to the design of the study. DV led the preparation of this manuscript. All other authors reviewed drafts and contributed to the writing.

Funding This research was managed by the Henry M. Jackson Foundation for the Advancement of Military Medicine, Inc. (HJF); and collaboratively sponsored by the Bob Woodruff Foundation, Health Net Federal Services, The Heinz Endowments, HJF, Lockheed Martin Corporation, May and Stanley Smith Charitable Trust, National Endowment for the Humanities, Northrop Grumman, Philip and Marge Odeen, Prudential, Robert R. McCormick Foundation, Rumsfeld Foundation, Schultz Family Foundation, Walmart Foundation, Wounded Warrior Project, Inc., and the Veterans Health Administration Health Services Research and Development Service.

Disclaimer The views expressed in this article are those of the authors and not an official position of any institution or funder.

Competing interests None declared.

Patient consent Obtained.

Ethics approval VA Boston Healthcare System; ICF International.

Provenance and peer review Not commissioned; externally peer reviewed.

Data sharing statement Twelve months following completion of the study, deidentified data will be made available to the broader community of veteran researchers to support secondary analyses of research questions related to veterans' well-being and programme use throughout the military-to-civilian transition. Information on the availability of this data set will be provided on the Henry M. Jackson Foundation website.

Open access This is an Open Access article distributed in accordance with the Creative Commons Attribution Non Commercial (CC BY-NC 4.0) license, which permits others to distribute, remix, adapt, build upon this work non-commercially, and license their derivative works on different terms, provided the original work is properly cited and the use is non-commercial. See: http://creativecommons.org/ licenses/by-nc/4.0/

(C) Article author(s) (or their employer(s) unless otherwise stated in the text of the article) 2018. All rights reserved. No commercial use is permitted unless otherwise expressly granted.

\section{REFERENCES}

1. U.S. Government Accountability Office. Better understanding needed to enhance services to veterans readjusting to civilian life (GAO14-676). 2014:1-55 http://www.gao.gov/assets/670/665725.pdf (accessed 13 Nov 2017).

2. Bowling UB, Sherman MD. Welcoming them home: supporting service members and their families in navigating the tasks of reintegration. Prof Psychol Res Pr 2008;39:451-8.

3. Castro CA, Kintzle S, Hassan AM. The combat veteran paradox: paradoxes and dilemmas encountered when reintegrating combat veterans and the agencies that support them. Traumatology 2015;21:299-310.

4. Elbogen EB, Johnson SC, Wagner HR, et al. Financial well-being and postdeployment adjustment among Iraq and Afghanistan war veterans. Mil Med 2012;177:669-75.

5. Wilcox SL, Oh H, Redmond SA, et al. A scope of the problem: Postdeployment reintegration challenges in a National Guard Unit. Work 2015;50:73-83.

6. Institute of Medicine. Returning home from Iraq and Afghanistan: assessment of readjustment needs of veterans, service members, and their families. Washington, DC: National Academies Press, 2013.

7. Sayer NA, Noorbaloochi S, Frazier P, et al. Reintegration problems and treatment interests among Iraq and Afghanistan combat veterans receiving VA medical care. Psychiatr Serv 2010;61:589-97.

8. Vogt D, Smith BN, Fox AB, et al. Consequences of PTSD for the work and family quality of life of female and male U.S. Afghanistan and Iraq War veterans. Soc Psychiatry Psychiatr Epidemiol 2017;52:341-52.

9. Berglass N, Harrell MC. Well after service: veteran reintegration and American Communities. 2012:1-45. https://www.cnas.org/ publications/reports/well-after-service-veteran-reintegration-andamerican-communities (accessed 13 Nov 2017).

10. Pedersen E, Eberhart N, Williams K, et al. Public-private partnerships for providing behavioral health care to veterans and their families: What do we know, what do we need to learn, and what do we need to do? 2015. http://www.rand.org/pubs/research_reports/RR994.html (accessed 13 Nov 2017).

11. American Psychological Association, Presidential Task Force on Military Deployment Services for Youth, Families, and Service Members. The psychological needs of U.S. Military service members and their families: a preliminary report. 2007. https://www.apa. org/about/policy/military-deployment-services.pdf (accessed 13 November 2017).

12. Clifford P, Graeser N. Navigating the "sea of goodwill:" Lessons from regional veterans collaboratives. J Community Pract 2016;24:319-32.

13. Crocker T, Powell-Cope G, Brown LM, et al. Toward a veteran-centric view on community (re)integration. J Rehabil Res Dev 2014;51:xi-xvii.

14. Mattox T, Pollard M. Ongoing survey research on post $9 / 11$ veteransRAND Corporation. 2016. http://www.rand.org/pubs/research_ reports/RR1532.html (accessed 13 November 2017).

15. Gray GC, Chesbrough KB, Ryan MA, et al. The Millenium Cohort Study: a 21-year prospective cohort study of 140,000 military personnel. Mil Med 2002;167:483-8.

16. Pinder RJ, Greenberg N, Boyko EJ, et al. Profile of two cohorts: UK and US prospective studies of military health. Int $J$ Epidemiol 2012;41:1272-82.

17. Thompson J, Hopman W, Sweet J, et al. Health-related quality of life of Canadian Forces veterans after transition to civilian life. Can $J$ Public Health 2013;104:15-21.

18. Aslan M, Concato J, Peduzzi PN, et al. Design of "neuropsychological and mental health outcomes of operation 
Iraqi freedom: a longitudinal cohort study". J Investig Med 2013;61:569-77.

19. Gray GC, Chesbrough KB, Ryan MA, et al. The millennium Cohort Study: a 21-year prospective cohort study of 140,000 military personnel. Mil Med 2002;167:483-8.

20. Seal KH, Bertenthal D, Miner CR, et al. Bringing the war back home: mental health disorders among 103,788 US veterans returning from Iraq and Afghanistan seen at Department of Veterans Affairs facilities. Arch Intern Med 2007;167:476-82.

21. US Government Accountability Office. Military and Veteran Support: DOD And VA Programs That Address the Effects of Combat and Transition to Civilian Life (GAO-15-24). 2014. http://www.gao.gov/ assets/670/666801.pdf (accessed 13 Nov 2017).

22. Armstrong NJ. McDonough JD, \& Savage D. Driving community impact: The case for local, evidence-based coordination in veteran and military family services and the Americaserves initiative. 2015. https://ivmf.syracuse.edu/article/1857/ (accessed 13 Nov 2017).

23. Copeland JW, Sutherland DW. Sea of Goodwill: Matching the donor to the need. 2010. Retrieved from office of the joint chiefs of staff, warrior and family support. 2010. http://www.jcs.mil/Portals/36/ Documents/CORe/SOGW_donor_to_need.pdf (accessed 13 Nov 2017).

24. Guo C, Pollack J, Bauman M. Ten frequently asked questions about veterans' transition: Results of a decade of RAND work on veteran life. 2016. http://www.rand.org/content/dam/rand/pubs/research reports/RR1000/RR1095/RAND_RR1095.pdf (accessed 13 Nov 2017).

25. Perkins DF, Aronson KR, Karre J, et al. Reducing barriers to evidence-based practice with military families: clearinghouse for military family readiness. Military Behavioral Health 2015;4:47-57.

26. Saturni S, Bellini F, Braido F, et al. Randomized Controlled trials and real life studies. Approaches and methodologies: a clinical point of view. Pulm Pharmacol Ther 2014;27:129-38.

27. Cooper A. Coordinating advances in understanding Veterans' wellbeing: the Veterans Research Hub. Journal of Military, Veteran, and Family Health 2016;2:5-7.

28. Marcus L, Ashkenazi I, Dorn B, et al. The five dimensions of metaleadership-harvard school of public health, national preparedness leadership initiative. 2008. http://www.hcna.net/pdf/Meta Leadership_Distribution1.pdf (accessed 13 Nov 2017).

29. Hong L, Page SE. Groups of diverse problem solvers can outperform groups of high-ability problem solvers. Proceedings of the National Academy of Sciences of the United States of America. 2004;101:16385-9.

30. Campbell LG, Mehtani S, Dozier ME, et al. Gender-heterogeneous working groups produce higher quality science. PLoS One 2013;8:e79147.

31. Freeman RB, Huang W. Collaborating with people like me: ethnic co-authorship within the US (NBER Working Paper No. 19905). 2014. www.nber.org/papers/w19905 (accessed 13 Nov 2017).

32. Sung NS, Crowley WF, Genel M, et al. Central challenges facing the national clinical research enterprise. JAMA 2003;289:1278-87.
33. U.S. House of Representatives, Committee on Energy and Commerce. The National Football League's attempt to influence funding decisions at the National Institutes of Health. 2016. https://democrats-energycommerce.house.gov/sites/democrats. energycommerce.house.gov/files/Democratic\%20Staff\%20Report\% 20on\%20NFL\%20NIH\%20Investigation\%205.23.2016.pdf (accessed 13 Nov 2017).

34. Cummings JN, Kielser S. Collaborative research across disciplinary and organizational boundaries. Social Studies of Science 2005;35:703-22.

35. Murray R, Spiegel J, Schiller R, et al. Schaum's outline of probability and statistics. 4th Edn. New York, NY: McGraw-Hill, 2013.

36. Defense Manpower Data Center (DMDC), Research, Surveys, and Statistics Center (RSSC). Status of forces surveys of active duty members (2013 \& 2014 SOFS-A): Briefing on leading indicators, Military OneSource, financial health, family life, access to technology, impact of deployments, and permanent change of stations (PCS) moves. 2016. http://download.militaryonesource.mil/12038/MOS/ Reports/SOFS-A_Briefing_20160311.pdf ((accessed 13 Nov 2017)).

37. Coughlin SS, Aliaga P, Barth S, et al. The effectiveness of a monetary incentive on response rates in a survey of recent U. S. Veterans. Survey Practice 2011.

38. Dillman DA, Smyth JD, Internet CLM. mail, and mixed-mode surveys: the tailored design method. New York, NY: Wiley \& Sons, 2011.

39. Czajka J, Beyler A. Declining Response Rates in Federal Surveys: Trends and Implications-U.S. Department of Health \& Human Services, Office of the Assistant Secretary for Planning and Evaluation. 2016. https://aspe.hhs.gov/system/files/pdf/255531/Decl iningresponserates.pdf (accessed 13 Nov 2017).

40. Mercer A, Caporaso A, Cantor D, et al. How much gets you how much? Monetary incentives and response rates in household surveys. Public Opin Q 2015;79:105-29.

41. Meyer T. Serving those who serve: A wise giver's guide to assisting Veterans and military families. In: Zinsmeister K, ed. Washington, DC: The Philanthropy Roundtable, 2013.

42. Kalton G, Flores-Cervantes I. Weighting Methods. J Off Stat 2003;19:9781-97.

43. Morgan NR, Davis KD, Richardson C, et al. Common components analysis: an adapted approach for evaluating programs. Eval Program Plann 2018;67:1-9.

44. Lo B. Sharing clinical trial data: maximizing benefits, minimizing risk. JAMA 2015;313:793-4.

45. Piwowar HA, Becich MJ, Bilofsky $\mathrm{H}$, et al. Towards a data sharing culture: recommendations for leadership from academic health centers. PLoS Med 2008;5:e183-9.

46. Chan D. So why ask me? Are self-report data really that bad? In: Lance CE, Vandenberg RJ, eds. Statistical and methodological myths and urban legends: Doctrine, verity and fable in the organizational and social sciences. New York, NY: Routledge Taylor \& Francis Group, 2008:309-36.

47. Spector PE. Method variance in organizational research: truth or urban legend? Organizational Research Methods 2006;9:221-32. 